\title{
Assessing children for the courts
}

\section{Caroline Lindsey}

In recent years, there has been growing recognition of the significant incidence of child abuse and neglect in the population, and of its adverse effect on the development of children and their mental and physical health. This awareness has led, especially following the implementation of the Children Act 1989, to an increased demand for psychiatric assessments of children for the courts by social services, solicitors, guardians ad litem and the courts themselves. There has been some reluctance to take up this work, for two main reasons. First, there has been concern that these time-consuming assessments will result in a shift of resources away from treatment, thus having an adverse impact on the balance of child mental health services. In some areas, the need has been recognised within the commissioning and contracting processes. Provision has been increased accordingly, acknowledging that it is part of the responsibility of the health authorities to assist the local authorities in this way.

Second, court work is professionally demanding. It requires the translation of psychological understanding, based on diverse theoretical frameworks, albeit increasingly supported by a growing body of research, into legally acceptable evidence. The responsibility for contributing to the court's decision-making about the child's future is considerable. The adversarial judicial system is challenging to the professional's expertise and, as a result, the court appearance is frequently very stressful. The imperative, in the medico-legal context, for the child psychiatrist to be objective in diagnosis and prognosis needs to be balanced with a coherent, dynamic account of how the problems involving the family with the court have come about.

Nevertheless, the assessment for the court may provide a unique opportunity to influence positively the lives of children and their families and to increase their emotional well-being. Therefore, every child psychiatrist needs to acquire the knowledge and develop the skills required for this work. In addition, psychiatrists from other subspecialities, especially forensic, general adult and learning disability, are often asked to provide reports about their patients whose children are the subjects of court proceedings. It is important for the psychiatrist to take account not only of the beneficial effects of parenthood for their patient, but also of the impact of the impairment of parenting capacity, by virtue of mental illness or personality disorder, on the child. For example, it is essential to recognise the sometimes irreconcilable differences in the time-scale of the rehabilitation of a person suffering from a serious psychiatric disorder and the urgent requirement to meet the needs of young children for secure attachment and permanence in their lives (Solnit et al, 1973). Hence, all psychiatrists need an awareness of the key issues involved in assessing children for the courts.

\section{Who assesses children for the courts?}

Although the child psychiatrist is most frequently called upon to assess children for the courts, he or she is usually a member of a multi-disciplinary team in a child mental health service. This may comprise child psychologists, child psychotherapists, family therapists, nurses and social workers who will often contribute to the assessment from their particular perspectives. They may also offer assessments in their own right, either as professional or expert witnesses.

Caroline Lindsey is a Consultant Child and Adolescent Psychiatrist and Systemic Family Therapist. She has been the Head of the Child and Family Department of the Tavistock Clinic (Child and Family Department, 120 Belsize Lane, London NW3 5BA) for the past six years. She has had a great deal of experience in the field of child care consultation and has a special interest in the field of fostering and adoption. 
Child psychologists use standardised tests that provide information about the child's developmental stage, intellectual ability and educational achievements: discrepancies between measurements are often an indication of emotional deprivation. They also may offer assessment of aspects of parent-child interaction, for example, of attachment and of parenting behaviour, as in the 'parent-child game' (Forehand \& McMahon, 1988). Projective tests provide a picture of the child's emotional experiences and a view of their perception of significant relationships, by means, for example, of the standardised interpretation of the stories told in response to the stimulus of pictures of animals in a variety of situations, as in the Children's Apperception Test, the Draw-AMan Test or Kinetic Family Drawings. The child psychotherapist and family therapist may contribute a view of the 'treatability' of the child or the family, which may be central to the issue of rehabilitation following family breakdown.

Paediatricians, especially those working in the community and having responsibility for child protection, also provide reports for the court. They are often the first professional to identify the child as at risk, or as having suffered abuse or neglect. In addition, their opinion may be sought regarding specific aspects of the child's health or development during the course of the overall assessment and may call for investigations to be carried out where appropriate (e.g. an electroencephalogram).

\section{Role of the expert witness}

The professional witness is expected to report to the court on their direct clinical work with the child and the family. By contrast, the expert witness may be asked for an opinion, sometimes without even having seen the child concerned. Experts are the only witnesses who are allowed to give an opinion in court. They should decline to offer a view if they do not feel competent to do so, either because they have not considered the particular issue in the assessment or because it is not within their field of expertise. Experts are expected to present their assessment, carry out research where appropriate, and may be asked to comment on the evidence of other witnesses, including colleagues. Sir Stephen Brown, President of the Family Division in the High Court, has stated that:

the court must have confidence in the expertise and integrity of the expert, especially their ability to give an unbiased assessment of the facts, to maintain neutrality, and to avoid assuming an advocate role. (Tufnell, 1993)
Inevitably, the child psychiatrist will hold views about the case and about child care in general, which are based on training and experience. These may be at variance with those of other professionals. The powerful emotions involved in discussion of issues such as with whom a child should live or whether they can return to live with their family, are unlikely to leave the clinician untouched. In order to try to ensure a balanced view, it is essential for the psychiatrist to involve the multi-disciplinary team in discussion of the case or to seek consultation from a colleague.

\section{Context of the assessment - who is assessed?}

The child may be the subject of the assessment, but it is the family context created by the pattern of relationships in the family, the multigenerational beliefs and experiences concerning parenthood and the significance of this particular child to these particular parents, which gives crucial meaning to the behaviour and emotions expressed by the child. The assessment of the child within the school context provides another perspective on the meaning of the child's behaviour. Teachers are often the trusted adults to whom children confide and their views are crucial (Lindsey, 1994).

Once a case enters the court arena, the context of the assessment is immediately extended beyond the child, the family and the school. It includes the professional network of social workers, guardian ad litem, teachers, solicitors, court welfare officers, foster carers and other health professionals. The assessment of the child requires the assessment of the inter-relationships between all the members of the family-professional system involved. Profound disagreements about the needs and capacities of the child and family often emerge in discussions with the professionals. These may arise because of differences in roles and responsibilities, and because of agency policy regarding child care and the availability of financial and human resources. For example, the social worker who has been monitoring the family on the child protection register may have observed, over months or years, a consistent inability in the parents to meet the child's needs so that the child appears neglected and is failing to thrive. The social services department may be viewed with suspicion and lack of trust by the family, exacerbated by their experience of frequent changes in workers because of the rapid turnover in staff 
which is very common in some areas. The guardian ad litem, who is appointed by the court on behalf of the child, and is therefore new to the family, may be able to elicit more hopeful attitudes and understanding of the child's needs in an interview with the parents. The foster carer may describe a child who has flourished since removal from home, showing a marked change in mood and the development of new skills. The child may ask to go home and show increased disturbance in the foster placement following contact with her/his family. These varying descriptions of the child and family arise largely because of the contextual differences in the relationships of the participants. There may then be differences of opinion about the possibilities for rehabilitation of the child with the family and about the resources needed. Ideally, the process of the assessment involves the elucidation, explanation and resolution of these differences.

\section{Consent to assessment}

The court will have given directions for an assessment in most cases, although there may be some circumstances in which a social services department or a general practitioner (GP) may have already requested an assessment, with the family's agreement, prior to the start of the proceedings. Under the Children Act 1989, children may refuse to participate in an assessment, even if the court has ordered it, if they are considered to have sufficient understanding to make an informed decision. Their age, intelligence, maturity and psychological state have to be taken into account in deciding this issue.

\section{Why request assessment}

Requests for assessments arise in the public domain, in care and adoption proceedings, and in the private domain, where there are proceedings after marital separation and divorce concerning residence and contact. They are also requested in compensation claims.

The questions to be addressed should be provided in writing at the outset of the assessment. The fundamental questions which may be asked are:

(a) Does the child have a psychological disturbance or developmental delay? Is it attrib- utable to the care he or she has been receiving? If so, how can it be ameliorated?

(b) Will the plans proposed for the child's future care be likely to improve or to jeopardise the child's mental health?

Inevitably, these questions are intimately linked to the further question: where should the child live and with whom should he or she have contact?

These questions are posed in a range of situations: the effect on the child of physical, emotional and sexual abuse, neglect, cruelty and rejection; factitious illness, failure to thrive and gross developmental delay; parental mental illness, personality disorder, addiction and learning disability and their impact on parenting capacity; the implications of divorce proceedings for the care of the child; and placement decisions once the child is already in alternative care (Black et al, 1991).

Assessment of whether a child has suffered sexual abuse is usually undertaken by the child protection teams. However, where there are particular difficulties posed in communicating with, for example, preschool children and children with a learning disability, child mental health professionals may be called upon to assess whether abuse has occurred. This may entail specialised techniques, such as the use of anatomically correct dolls.

Assessment of children who commit serious crime, involving violence and sexual offences, is best referred to forensic child psychiatry services. It is important to remember that these children are usually also the victims of abuse and may be in need of protection themselves. The assessment of the child's needs and the possibility of rehabilitation with the family, once the question of the abuse has been considered, is commonly requested.

\section{Process of assessment}

Permission should be obtained from the court for the full disclosure of all previous reports. Up-todate information from the school and nursery, GP, health visitor, social workers, adult psychiatrists and other professionals involved is required.

\section{Who is seen?}

The professional network meeting involves the key professionals in the case and must include those who have statutory responsibility and authority 
for decision-making. It sets the agenda for the assessment, clarifying the questions to be considered and the areas of agreement and disagreement. Ideally, it should result in the child psychiatrist receiving the support to carry out the assessment in full. It is an opportunity to obtain a family geneogram and a chronology of family events, including details of all the moves and admissions to hospital which the child has experienced.

The assessment will normally include an assessment of the child, the family, the parents and/or carers in the context of the wider social setting. The child will usually be interviewed, possibly on more than one occasion, on their own. Meetings with various combinations of family members, with and without the child may be relevant. These are likely to include interviews of the parents, separately and together. If they are in regular contact with the child and it is considered to be in the child's interests to do so, they may be seen with the child. If there are other siblings involved, the whole family is seen together. Bringing a child and family together for the first time since separation because of rejection or allegations of abuse, may sometimes be required as part of the assessment, but it needs to be carefully prepared. If contact visits are occurring, it is useful to observe one of these and incorporate it into the assessment. Foster carers and adoptive parents are also interviewed, with or without the child, depending on the circumstances. Meetings in the family's own home, seeing the child in the foster home or in the children's home, and school visits may all be helpful.

The assessment is completed by a case conference at which the findings are described and discussed, and an attempt is made to reach a consensus. It is also an opportunity for discussion of the implementation of the recommendations, if accepted by the court, since the court expects a fully worked out care plan to be presented.

\section{Principles of assessment}

At the outset, it is necessary to ascertain that all the participants have agreed and understand why there is to be an assessment. The roles and responsibilities of the psychiatrist and the judge should be explained. Where families have previously been involved in treatment, the difference should be clarified.

The assessment should be a therapeutic process, which enables all the family members to tell their story, ensuring that they feel that they have been heard, even if their view is not upheld. The assessment sanctioned by the court may provide the opportunity for a brief intervention in a system that has so far been stuck in an unresolved conflict, either between partners or between the family and statutory agencies. For example, the discussion may help parents to gain an understanding of why their child has been removed and allow them to shift to a position where they can give permission for the child to move on. This may make a difference to whether it is possible for the child to maintain contact with them or not. In one case, a child of a mother who misuses alcohol was being placed for adoption, against her wishes, after several years of attempting to maintain them together. During the course of the interview, in which she had described her plans to bring him home to live with her, she gradually became very sad and thoughtful. She recognised her inability to provide him with the care he needed, but wanted her love for him to be acknowledged. As she began to think about giving up her role as parent, it became possible to consider asking the adoptive parents to agree to keep in touch with her, knowing that she would no longer undermine them. Following a further meeting with the adoptive parents, they, in turn, could then recognise the child's tie to his mother as significant, without feeling threatened.

It is important to offer the child and the family feedback from the assessment, although they do not always wish to take advantage of this. This is also another opportunity for therapeutic work with the family. It is certainly preferable that they do not learn about the outcome of the assessment by reading the court report or via the solicitor.

\section{The Children Act 1989}

The assessment is guided by the principles laid down in the Children Act 1989 and the report should be written with these in mind (Box 1). The time-scale of the assessment should be realistic, while avoiding unnecessary delay. The child's welfare is paramount and the wishes of the child about their future must be discovered. The child is ideally best taken care of by the family, which should be kept together wherever possible. Professionals are expected to work 'in partnership with parents'. The court is enjoined not to make an order unless it would definitely benefit the child. The circumstances under which this is likely to be the case are where the child has suffered or there is a danger that the child will suffer significant harm. This concept (Box 2) is defined as a failure of the parents to provide care to the 
Box 1. The welfare of the child

The child's welfare is the court's paramount consideration

Delay is likely to prejudice the welfare of the child

The court will not make an order unless it is better for the child than making no order

The court, and any person giving advice, should have regard to:

(a) the ascertainable wishes and feelings of the child (considered in the light of his/her age and understanding);

(b) the child's physical, emotional and educational needs;

(c) the likely effect on the child of any change in his/her circumstances;

(d) the child's age, gender, background and any personal characteristics which the court considers relevant;

(e) any harm which the child has suffered and which the court considers relevant; and

(f) how capable each of the parents (and any other persons in relation to whom the court considers the question to be relevant) are of meeting the child's needs.

particular child, resulting in harm that can take a variety of forms, including ill-treatment, neglect and developmental delay, as well as the child being beyond the control of the parents.

\section{The wishes of the child}

This is an area fraught with difficulties for the child and the professional. How does the professional interpret what the child says? Is the child free to say what they mean, and do they mean what they say? How are family loyalty, fear arising from threats and loss of relationship, and hope for a better future influencing their responses? How do cultural beliefs about family ties influence their answers? The age, cognitive ability and developmental stage will affect the extent to which the child should be allowed to influence crucial decisions about the future of the family, for example, the choice between parents following divorce. The nature of their attachment to the parents has to be considered. The anxiously attached child who fears further rejection, or those who have experienced long-standing abuse, where the relationship with the abusive parent is allimportant, may fear the break-up of the family and ask to return. The court has to balance the need for protection and the child's identification with the family.

\section{Assessment of the child}

The meeting with the child is used:

(a) to observe his or her interaction in the waiting room, with the carers and with the professional; (b) to enable the child to communicate, by talking and by making use of the play material provided, aiding assessment of his or her mental state, self-esteem and preoccupations;

(c) to explore the child's understanding of the purpose of the meeting and to explain, if appropriate; and

(d) to gauge the level of physical care and health, motor, speech and language and cognitive development.

There is a balance to be struck between allowing the child to communicate in a free-flowing way and giving a focus to the conversation by asking

Box 2. Threshold criteria for making a care order or supervision order

If the child concerned is suffering significant harm, or is likely to suffer significant harm

The harm or likelihood of harm is attributable to: the care given to the child, or likely to be given if the order were not made, not being what it is reasonable to expect from a parent; or the child's being beyond parental control

Harm is defined as ill-treatment, which includes physical, sexual and emotional abuse and impairment of physical and mental health and developmental problems attributable to the failure of the parents to give appropriate care 
questions. While leading questions are usually avoided, open questions allow the child to give more detailed descriptions of experiences at home and at school.

Using figures to represent family members and drawing the family enables the child to talk about relationships, and to tell the story of important family events. Children's play and their drawings give an important indication of their experiences, including those of abuse. Asking children to say what they would do with three wishes often provides useful insight into their hopes and understanding of their situation.

The question of the validity of the child's report is often raised by lawyers. There is good evidence that children are capable of accurate recall, and even young children can recall important events in the right sequence (Angold, 1994). A child's description of adverse events is likely to be based on reality, if it is outside the norm for either the experience or fantasy life of a child of that age and background. Children may rarely be rehearsed to report abuse that did not occur. However, the affect that accompanies the story, the child's language and perspective will normally offer validation of the account.

\section{Assessment of child with parent}

This provides an opportunity to assess: the quality of the relationship between the child and the parent, and of the parenting capacity; their capacity to express mutual affection; the nature of parental discipline and control; the level of awareness of the child's age, appropriate needs and responsiveness to them; the ability to see the child as separate from the parent; and the child's ability to communicate with the parent and turn to her/him for comfort and help. With young children, it is useful to observe a separation and reunion with the parent to see how they respond, using the categories of secure and insecure attachment as a framework (Ainsworth et al, 1978).

\section{The family interview}

Seeing the family in their own home provides important information about their parenting capacity and way of life. Cultural differences in understanding of psychological problems and of beliefs about child rearing in families from ethnic minorities need to be recognised. The meeting with the family offers the opportunity to:

(a) assess the emotional tone of their interaction and the patterns of communication of the parents and children with each other and with the psychiatrist;

(b) to observe the alliances within the family, and generational boundaries;

(c) to elicit their accounts of the problems and to discuss the differences of perspective between them and their solutions; and

(d) to assess the capacity of the family to recognise the need for change and their willingness to participate in therapy.

\section{Assessment of the parents}

The interview with the parents together and separately needs to: address their functioning as a marital and parental couple; elicit the stories of their childhood and family experiences, with particular regard to histories of adversity such as abuse, violence and neglect and their explanations for these experiences, as well as evidence of successful functioning, competence and skills; explore histories of emotional disturbance, substance misuse and mental illness and its impact on their parenting and to assess their current mental state; discuss their care of their children, the extent to which they recognise a problem, their sense of responsibility for it and their hopes and plans for the future; and assess their capacity to work in collaboration with professionals.

\section{The court report}

The court report needs to address the questions posed by the court within a formal framework (Box 3) (see Tufnell, 1993). It forms the basis for the evidence that may be required to be given in court and on which the psychiatrist will be crossexamined. It may be helpful to remember to guard against the dangers of certainty, created by the title of expert, and at the same time, attempting to assist the court with a balanced view and considered solutions.

\section{Concluding remarks}

In this paper, while the commonalities of the assessment have been addressed, it has not been possible to give due consideration to the particular issues which arise, for example, in the assessment of whether a child should be fostered or adopted, the optimum level of contact post-placement, in 
Box 3. Guidelines for court reports

Give your name, position and qualifications

Give details of the subject and court proceedings

The introduction should include: the reason for the report; sources of information; and a summary of undisputed facts and outstanding questions

Give an account of the assessment, separating content, process and conclusions drawn

The discussion should: address questions asked; address the welfare checklist; consider a psychiatric formulation and diagnostic classification where appropriate; and draw on research evidence where applicable

Give conclusions and recommendations

Consider a summary if the case is complex and the report is lengthy

the consideration of the risk of future abuse, treatability and so on. Child psychiatrists have a crucial role to play in the promotion of the welfare of children and their families, within the legal context. Their training can enable them to assist the court to make the most powerful and farreaching interventions into the lives of children. The presentation of a coherent synthesis of findings and recommendations is informed by an understanding of dynamic family processes and psychopathology, is underpinned by knowledge of research, and integrates the contribution of other professionals. But most importantly, it is based on the unique relationship with the individual children and their families.

\section{References}

Ainsworth, M. D. S., Blehar, M. C., Waters, E.,et al (1978) Patterns of Attachment: A Psychological Study of the Strange Situation. Hillsdale, NJ: Erlbaum.

Angold, A. (1994) Clinical interviewing with children and adolescents. In Child and Adolescent Psychiatry (eds M. Rutter, E. Taylor \& L. Hersov), pp. 51-63. Oxford: Blackwell.

Black, D., Wolkind, S. \& Harris Hendriks, J. (eds) (1991) Child Psychiatry and the Law. London: Gaskell.

Forehand, R. L. \& McMahon, R. J. (1988) Helping the NonCompliant Child: A Clinician's Guide to Parent Training. New York: Guilford Press.

Lindsey, C. (1994) The Children Act 1989. Implications for the family and the school. In The Family and the School. A Joint
Systems Approach to Problems with Children (eds E. Dowling \& E. Osborne), pp. 160-168. London: Routledge.

Reder, P. \& Lucey, C. (eds) (1995) Assessment of Parenting. Psychiatric and Psychological Contributions. London: Routledge.

Solnit, A. J., Freud, A. \& Goldstein, J. (1973) Beyond the Best Interests of the Child. London: The Free Press.

Tufnell, G. (1993) Psychiatric court reports in child care cases: what constitutes 'good practice'? ACPP Review and Newsletter, 15, 219-224.

(1994) Points of law. ACPP Review and Newsletter, 16, 206-209.

\section{Multiple choice questions}

1. Threshold criteria for making a care order or supervision order include:

a if the child concerned is suffering significant harm

b if the child has committed a criminal offence

c if the child is beyond parental control

$d$ if the child is not going to school

e the likelihood of future harm.

2. The welfare checklist in the Children Act 1989 includes the need to take into account:

a ascertainable wishes and feelings of the child

b the likely effect of change in the child's circumstances

c the parents' wishes

d the child's physical, emotional and educational needs

e how capable the parents are of meeting the child's needs.

3. The role of the expert witness is:

a to report on their clinical assessment and treatment

b to offer an opinion based on their own assessment

c to present the needs of the child

d to be an advocate for their patient

e to offer an opinion based on another professional's assessment and/or treatment.

\begin{tabular}{|cll|}
\hline MCQ answers & & \\
$\mathbf{1}$ & 2 & 3 \\
a T & a T & a T \\
b F & b T & b T \\
c T & c F & c F \\
d F & d T & d F \\
e T & e T & e T \\
\hline
\end{tabular}

